\title{
(2) OPEN ACCESS \\ Complete heart block in cardiac sarcoidosis reversed by corticosteroid therapy: time course of resolution
}

\author{
Anna Tomdio 다, ${ }^{1}$ Huzaefah Syed ${ }^{2}$ Kenneth Ellenbogen, ${ }^{1}$ Jordana Kron ${ }^{1}$
}

${ }^{1}$ Cardiovascular Disease, VCU Health, Richmond, Virginia, USA ${ }^{2}$ Rheumatology, VCU Health, Richmond, Virginia, USA

\section{Correspondence to}

Dr Jordana Kron;

jordana.kron@vcuhealth.org

$\mathrm{HS}$ and KE contributed equally.

Accepted 15 February 2021

Check for updates

(c) BMJ Publishing Group Limited 2021. Re-use permitted under CC BY-NC. No commercial re-use. See rights and permissions. Published by BMJ.

To cite: Tomdio A, Syed $\mathrm{H}$ Ellenbogen $\mathrm{K}$, et al. BMJ

Case Rep 2021:14:e240834.

doi:10.1136/bcr-2020

240834

\section{SUMMARY}

A 53-year-old man was admitted for recurrent syncope and found to have complete heart block (CHB). Cardiac magnetic resonance imaging MRI) showed extensive patchy late gadolinium enhancement in the apical and lateral walls, consistent with cardiac sarcoidosis (CS) but no scar in the septum. A fluorodeoxyglucose (FDG)positron emission tomography showed FDG uptake in the septum and basal lateral walls. Imaging suggested active inflammation in the septum affecting atrioventricular (AV) conduction but no irreversible fibrosis. Diagnosis of isolated CS requires a high level of suspicion and multidisciplinary teamwork involving heart failure specialists, electrophysiologists and rheumatologists. After specialist and patient discussion, treatment of the disease was initiated with prednisone $40 \mathrm{mg}$ daily, 11 months after presenting with CHB. Three weeks later, ECG with pacing inhibited showed second-degree AV block Mobitz type II and 4 weeks later, AV conduction recovery. This highlights the importance of immediate therapy in reversing AV conduction abnormalities in CS.

\section{BACKGROUND}

Isolated cardiac sarcoidosis (CS) often escapes detection given no clinically apparent disease in other organs. Diagnosis requires high index of suspicion based on cardiac manifestations and advanced imaging modalities. Its presentation is usually that of an idiopathic atrioventricular block (AVB). Imaging may show active disease versus myocardial fibrosis which determines the benefit of immunosuppressant therapy. A patient with complete heart block $(\mathrm{CHB})$ received prednisone for suspected $\mathrm{CS}$ 11 months after presentation. Three weeks later, the underlying rhythm was second-degree AVB Mobitz II and 4 weeks after therapy initiation, he had atrioventricular (AV) conduction recovery. We report a case of improved AV conduction after a delayed diagnosis of CS as well as collaborative work between electrophysiologists, heart failure specialists and rheumatologists in the management of isolated CS.

\section{CASE PRESENTATION}

A 53-year-old Caucasian man with a history of obesity, fatigue for 7 years and right bundle branch block for 10 years was admitted at an outside facility for recurrent syncope. At the time of his presentation, he was found to have CHB on ECG. On physical examination, his blood pressure was $97 / 54 \mathrm{~mm} \mathrm{Hg}$ with a heart rate of 32 beats per minute. The rest of his examination was otherwise unremarkable.

\section{INVESTIGATIONS}

Prior to developing syncope with $\mathrm{CHB}$ and to having his care transferred to our facility, he underwent extensive evaluation of other symptoms which included dyspnoea and fatigue. A sleep study revealed severe sleep apnea for which he was placed on continuous positive airway pressure. Two trans thoracic echocardiograms (TTEs) 1 year apart showed an ejection fraction (EF) of $50 \%-55 \%$, with no valvular disease and normal atrial sizes. However, it revealed inferior wall hypokinesis and grade I diastolic dysfunction. An exercise stress echocardiogram revealed mid-inferior and inferoseptal infarction without ischaemia. Over the years, he had coronary angiograms due to continued concerns of dyspnoea which were negative for obstructive coronary artery disease. Multiple chest X-rays were negative for any cardiopulmonary processes. A chest CT revealed hepatic steatosis but no pulmonary process or lymphadenopathy. He then developed light-headedness and eventually, syncopal episodes. For the newly discovered $\mathrm{CHB}$ on ECG, he had a dual-chamber pacemaker implanted. During his follow-up clinic visits, he continued to have dyspnoea prompting another evaluation of his coronary arteries with a coronary angiogram which was again negative for obstructive disease. Seven months after his last TTE, he had cardiac magnetic resonance imaging (MRI) which showed an EF of 21\%. On pacemaker interrogation, he was noted to have episodes of sustained ventricular tachycardia (VT). His device was therefore upgraded to a cardiac resynchronisation therapy defibrillator. He did not have any physical signs of volume overload. At the time of the cardiac MRI, he was noted to be ventricular paced $86 \%$ of the time. Given the findings on imaging, he was referred to our facility for further evaluation and management of his heart failure.

On further evaluation at our institution, Lyme antibody titres were negative. During a 6-minute walk test, he ambulated $1480 \mathrm{ft}$ with no hypoxia. A repeat cardiac MRI showed extensive patchy late gadolinium enhancement (LGE) accounting for $16 \%$ of the left ventricle in the lateral and apical walls, concerning for CS (figure 1). EF was 21\% and the septum appeared hypokinetic. Due to concerns of CS, his care was collaborated between the advanced heart failure and sarcoidosis clinics in the electrophysiology department at our facility.

In order to determine whether he was having active inflammation due to sarcoidosis, he had a fluorodeoxyglucose-positron emission tomography (FDG-PET). This showed a large, severe perfusion defect in the mid-inferior, inferoseptal and basal 


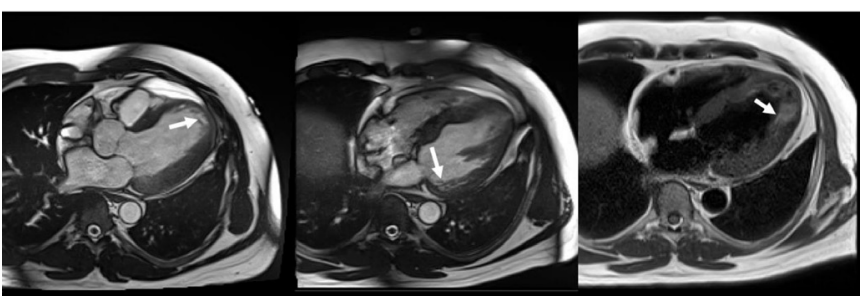

Figure 1 Cardiac MRI in horizontal axis showing extensive patchy late gadolinium enhancement in the lateral and apical walls typical of sarcoidosis (arrows).

anteroseptal walls with FDG uptake in the septum and basal lateral walls (figure 2). There was no FDG uptake of lymph nodes in the axilla, mediastinum or hila. Endobronchial ultrasound-guided lymph node biopsy was negative for inflammation or granuloma. Troponin levels were negative on two occasions. ACE levels were not obtained. An evaluation by a rheumatologist was negative for any skin manifestations of sarcoidosis. There was no concern for eye inflammation. Spirometry revealed mild restrictive lung disease with mildly reduced diffusing capacity of the lungs for carbon monoxide. Endomyocardial biopsy was offered to the patient; however, he declined.

\section{TREATMENT}

Given imaging findings on cardiac MRI and FDG-PET were suggestive of presumptive CS, prednisone $40 \mathrm{mg}$ daily was initiated 11 months after presentation with syncope and CHB. Systolic congestive heart failure was treated with carvedilol, eplerenone and sacubitril/valsartan. Due to hepatic steatosis, methotrexate was not initiated. However, azathioprine was initiated 2 months after prednisone, after obtaining thiopurine methyltransferase levels. TTE 3 months later showed an EF of 40\%-45\%. At follow-up, ECG with pacemaker inhibited showed second-degree AVB Mobitz type II at 3 weeks (figure 3A) and AV conduction recovery at 4 weeks (figure $3 \mathrm{~B}$ ). Steroid tapering was initiated and he has remained well on subsequent visits.

\section{OUTCOME AND FOLLOW-UP}

Four weeks after starting steroid therapy, the patient showed improvement in fatigue. Steroid tapering was initiated at that time. Three months after initiating heart failure treatment, he showed near-complete resolution of fatigue and dyspnoea. $\mathrm{He}$ has been able to return to work as a security officer with no limitations. He remains on guideline-directed medical therapy for heart failure and on azathioprine for management of CS.

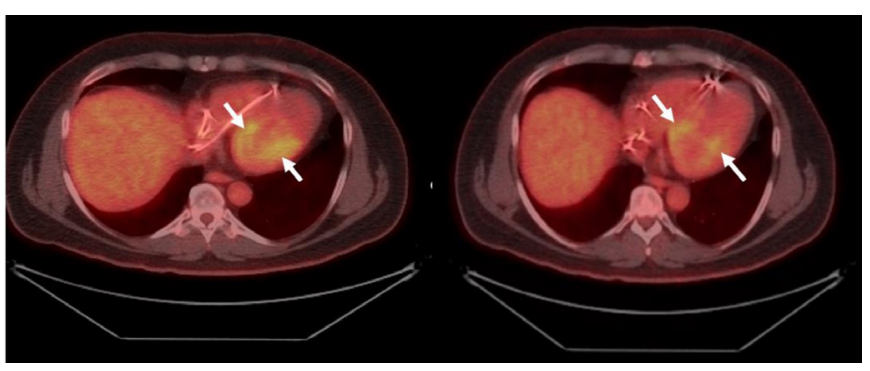

Figure 2 Transverse ${ }^{18} \mathrm{~F}-\mathrm{FDG}$ PET/CT images at the cardiac level, horizontal long axis, showing septal and lateral wall myocardial uptake (arrows). FDG, fluorodeoxyglucose; PET, positron emission tomography.

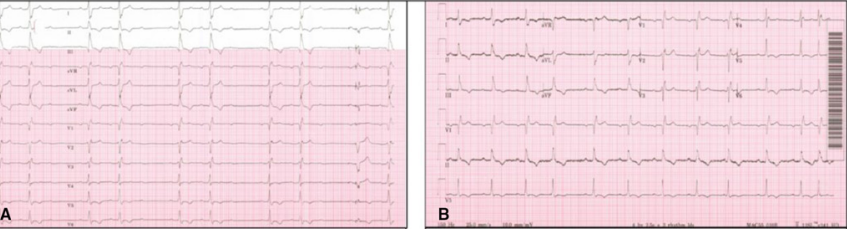

Figure 3 (A) ECG 3 weeks after steroid therapy demonstrating second-degree AV block Mobitz II. (B) ECG 4 weeks after steroid therapy demonstrating normal sinus rhythm with $A V$ conduction recovery. AV, atrioventricular.

\section{DISCUSSION}

Sarcoidosis is a multi-system granulomatous disorder that exhibits non-caseating granulomas in involved organs. This case presents a patient with CS whose $\mathrm{CHB}$ is reversed to normal $\mathrm{AV}$ conduction, nearly 1 year after initial diagnosis of $\mathrm{CHB}$ and 4 weeks after steroid therapy. Unfortunately, cardiac findings are discovered later in the disease even though CS often presents as an idiopathic AVB in young and middle-aged individuals. ${ }^{1}$ As recommended by the 2014 Heart Rhythm Society (HRS) Expert Consensus Statement, all patients younger than 60 years with unexplained Mobitz II or third-degree AVB should be screened for CS with high-resolution chest CT or advanced cardiac imaging with MRI or FDG-PET. ${ }^{2}$ In a study of 32 patients aged 18-60 years presenting with high-degree AVB with no history of sarcoidosis, 34\% had evidence of CS on FDG-PET. ${ }^{3}$ Identifying $\mathrm{CS}$ as the aetiology of high-degree AVB is critical. Nordenswan et al remarkably showed that the 5-year incidence of sudden cardiac death (SCD) was $9 \%$ in patients with CS with AVB and normal EF and the 5 -year incidence of SCD or VT was $24 \%{ }^{1}$

No prospective randomised trials have evaluated the benefit of corticosteroid therapy in patients with CS with $\mathrm{CHB}$; however, small uncontrolled trials have shown the benefit of glucocorticoid therapy in this patient population. In a retrospective study of 41 patients, $63 \%$ had clinical manifestations and $22 \%$ had electrical findings of sarcoidosis. ${ }^{4}$ Nine patients had nodal, suprahisian or infrahisian block identified via an EP study, and $75 \%$ of the patients had improvement in conduction after steroid therapy. In another study evaluating the rate of undiagnosed CS and giant cell myocarditis, there was a tendency toward less pacing on follow-up at 1 year related to early start of immunosuppression therapy after pacemaker implantation. ${ }^{2}$ AVB was reversible in 2 (13\%) of 16 patients after the institution of corticosteroid therapy. In a meta-analysis, $27(47.4 \%)$ of 57 patients with CS presenting with AVB who received steroid therapy showed improvement in AV conduction, compared with recovery in none of the 16 patients who did not receive steroids. ${ }^{5}$ The 2014 HRS Expert Consensus Statement gave a class IIa recommendation stating that immunosuppression can be useful in patients with CS with second-degree (Mobitz II) or third-degree AVB. ${ }^{2}$ While corticosteroids can reverse high-degree AVB in patients with $\mathrm{CS}$, the time course of resolution is not well defined. Our patient showed improvement from third degree to Mobitz II within 3 weeks and further improvement to sinus rhythm with AV conduction recovery in an additional 1 week.

In the case reported here, imaging revealed FDG uptake in the basal septum without evidence of LGE demarcating fibrosis on cardiac MRI. These findings suggest that this patient had ongoing granulomatous inflammation in the septum affecting AV conduction, but had not yet developed irreversible fibrosis in this region. Patients with fibrosis affecting the electrical 
conduction system are unlikely to have $\mathrm{AV}$ conduction recovery with steroids, while patients with earlier disease, who have inflammation but no or minimal fibrosis, are more likely to have conduction system improvement with treatment. The timing of progression from inflammation to fibrosis in patients with CS

\section{Patient's perspective}

I had been so tired for so long and could not quite understand why that was the case. I saw my primary care doctor a lot of times and had a lot of tests but nobody could explain why I was feeling the way I was. I did everything I was told to do. I used my CPAP machine but I was still tired. I tried to lose some weight but I did not feel better. I did a lot of other tests and everything always came back normal. I saw cardiologists and they could not find anything. Then, I started passing out. At first, I thought maybe I was working a lot or I was dehydrated but it happened again. That's when I went to the hospital and they told me my heart rate was very slow. That is why they put the pacemaker in my chest. I initially felt a little better but was not back to normal. I had to follow-up with a cardiologist. He then did the MRI of my heart which showed that my heart was not functioning normally. That is when he sent me to the heart failure specialist for congestive heart failure.

I did a lot of other scans. The MRI and the PET scan showed that I probably have sarcoidosis so he sent me to the electrophysiologist and the rheumatologist. It required a lot of drives back and forth to the hospital because I had so many tests and so many appointments scheduled but it was all worth it. I was very scared because I was not sure of what was going to happen. Initially, like I said, I was not back to normal and then my device had to be changed because of ventricular tachycardia. Those were very uncertain and scary times. It was a disease I had never heard of before and have since read a lot about it. I am glad I made it through and did what I was advised to do. I definitely feel a lot better now.

What is interesting is that nobody in my family has this but I am glad they found it. I can work, walk and I don't get as tired or short of breath as I did before. I can do more activities with my family. My heart is functioning better and I will continue to see all the doctors at your hospital. There are three I see there and one closer to my house because of how far I live. I tell my story a lot and if it helps even just one person, I am happy. This has all made a big difference and I am recovering well.

\section{Learning points}

- Isolated cardiac sarcoidosis (CS) is difficult to diagnose and often presents as conduction disease including complete heart block (CHB), or ventricular arrhythmia.

- The differential diagnosis for unexplained CHB in a young patient includes Lyme disease, congenital CHB, cardiac amyloid, Lamin A/C-mutation-related cardiomyopathy, giant cell myocarditis and CS.

- Early diagnosis and treatment of CS with corticosteroids, in the absence of myocardial fibrosis, could potentially revert conduction disease.

- In this case, multidisciplinary teamwork was crucial and necessary for accurate diagnosis and management. is not known and may differ from patient to patient. However, early diagnosis and treatment are critical to maximize the chance of improvement with therapy. How long into the disease process AVB may reverse is not known. Our patient had AV recovery with steroid initiation 11 months after presentation with AVB. In some patients with CS, fibrosis formation may be delayed and a late response to steroids may be achieved.

Our patient had suspected isolated CS based on imaging but did not have tissue biopsy confirming the diagnosis. Isolated CS can be particularly challenging to diagnose. In fact, the HRS Expert Consensus Statement requires endomyocardial biopsy to confirm isolated CS. The revised 2017 Japanese Ministry of Health and Welfare Diagnostic Guidelines allow for a diagnosis of isolated CS based on a combination of clinical and imaging findings without tissue diagnosis, ${ }^{6}$ and our patient had isolated CS based on these criteria. While the incidence of isolated CS is not known, with strict diagnostic criteria, it is likely quite rare. In one study using whole body FDG-PET to look for extracardiac inflammation, isolated CS was found in only 1 of 31 patients (3\%).

\section{CONCLUSION}

In this case study, we reported a patient with suspected isolated CS who reverted from CHB to Mobitz II heart block to normal AV conduction 4 weeks after starting corticosteroids, 11 months after development of CHB. This case highlights the importance of screening young patients with AVB for CS and the possibility of AV conduction recovery if irreversible fibrosis has not developed.

Contributors All of the authors have contributed to the preparation of the manuscript. Majority of the manuscript text was written by AT with major guidance from JK.

Funding The authors have not declared a specific grant for this research from any funding agency in the public, commercial or not-for-profit sectors.

Competing interests None declared.

Patient consent for publication Obtained.

Provenance and peer review Not commissioned; externally peer reviewed.

Open access This is an open access article distributed in accordance with the Creative Commons Attribution Non Commercial (CC BY-NC 4.0) license, which permits others to distribute, remix, adapt, build upon this work non-commercially, and license their derivative works on different terms, provided the original work is properly cited and the use is non-commercial. See: http://creativecommons.org/ licenses/by-nc/4.0/

\section{ORCID iD}

Anna Tomdio http://orcid.org/0000-0001-9178-4952

\section{REFERENCES}

1 Nordenswan H-K, Lehtonen J, Ekström K, et al. Outcome of cardiac sarcoidosis presenting with high-grade atrioventricular block. Circ Arrhythm Electrophysiol 2018;11:e006145.

2 Birnie DH, Sauer WH, Bogun F, et al. Hrs expert consensus statement on the diagnosis and management of arrhythmias associated with cardiac sarcoidosis. Heart Rhythm 2014;11:1304-23.

3 Nery PB, Beanlands RS, Nair GM, et al. Atrioventricular block as the initial manifestation of cardiac sarcoidosis in middle-aged adults. J Cardiovasc Electrophysiol 2014;25:875-81.

4 Chapelon-Abric C, de Zuttere D, Duhaut $P$, et al. Cardiac sarcoidosis: a retrospective study of 41 cases. Medicine 2004;83:315-34.

5 Sadek MM, Yung D, Birnie DH, et al. Corticosteroid Therapy for Cardiac Sarcoidosis: A Systematic Review. Can J Cardiol 2013;29:1034-41.

6 Terasaki F, Yoshinaga K. New guidelines for diagnosis of cardiac sarcoidosis in Japan. Ann Nucl Cardiol 2017:3:42-5.

7 Juneau D, Nery P, Russo J, et al. How common is isolated cardiac sarcoidosis? Extra-cardiac and cardiac findings on clinical examination and whole-body ${ }^{18} \mathrm{~F}-$ fluorodeoxyglucose positron emission tomography. Int J Cardiol 2018;253:189-93. 
Copyright 2021 BMJ Publishing Group. All rights reserved. For permission to reuse any of this content visit https://www.bmj.com/company/products-services/rights-and-licensing/permissions/

BMJ Case Report Fellows may re-use this article for personal use and teaching without any further permission.

Become a Fellow of BMJ Case Reports today and you can:

- Submit as many cases as you like

- Enjoy fast sympathetic peer review and rapid publication of accepted articles

- Access all the published articles

- Re-use any of the published material for personal use and teaching without further permission

Customer Service

If you have any further queries about your subscription, please contact our customer services team on +44 (0) 2071111105 or via email at support@bmj.com.

Visit casereports.bmj.com for more articles like this and to become a Fellow 